\title{
MOTIVAÇÃO PARA A APRENDIZAGEM CONSTRUÇÃO E VALIDAÇÃO DE UMA ESCALA DE AVALIAÇÃO
}

E. DUQUE*, J. MARQUES, K. SANTIAGO E S. NEVES

Faculdade de Filosofia e Ciências Sociais da Universidade Católica Portuguesa eduardoduque@braga.ucp.pt ${ }^{*}$

Artigo submetido em março/2016 e aceito em junho/2016

DOI: $10.15628 /$ holos.2016.4208

\section{RESUMO}

Do ponto de vista dos professores uma das questões fulcrais no processo de ensino/aprendizagem, é a falta de motivação dos alunos, seja pela inadequação do método de ensino, que não suscita situações motivadoras, seja porque o aluno simplesmente não tem vontade de estudar e, consequentemente, de aprender. Estudar a motivação para a aprendizagem envolve a compreensão de um complexo sistema de fatores que se interrelacionam, operando em conjunto na motivação do aluno. Com base nas investigações de Boruchovitch e Neves (2006), Siqueira e Wechsler (2006) e Simões e Alarcão (2011) que visavam a validação de uma escala para avaliar a motivação, e recorrendo a uma metodologia quantitativa, elaborou-se este estudo cujo objetivo é o de construir e validar uma escala de avaliação da motivação para a aprendizagem. O procedimento para a consecução deste objetivo compreendeu a construção do instrumento, de acordo com pressupostos teóricos; a aplicação num número adequado de sujeitos; a aplicação de outros instrumentos reconhecidos para o estudo da validade convergente e para verificação de hipóteses teóricas; a realização de uma Análise Fatorial para a composição dos itens nos fatores que determinaram o formato final do instrumento e, por fim, o estudo da estabilidade temporal por meio da aplicação do teste e do re-teste após um período de tempo. Os resultados obtidos permitem verificar que é possível medir a motivação para a aprendizagem, considerando-se relevante a necessidade de dar continuidade a esta investigação para compreender as verdadeiras motivações dos alunos, cuja análise se revela essencial para a criação de estratégias de combate ao insucesso escolar.

PALAVRAS-CHAVE: Avaliação, motivação, ensino, aprendizagem, escala de avaliação

\section{MOTIVATION FOR LEARNING CONSTRUCTION AND VALIDATION OF A RATING SCALE}

\begin{abstract}
From the teachers' point of view one of the key issues concerning the teaching/ learning process is the students' lack of motivation, either because of the inadequacy of the teaching methods, which do not create involving situations, or because the students simply don't want to study and consequently don't want to learn. To study motivation in learning involves a deeper understanding of a complex system of interrelated factors which operate as a whole in the students' motivation. We have based the present study on Boruchovitch and Neves (2006), Siqueira and Wechsler (2006) and Simões and Alarcão (2011), who defend the use of a quantitative scale to measure students' motivation, with the aim of setting up and validating evaluation tools on students' learning motivation. Our practical procedure consisted on the
\end{abstract}

designing of these instruments, following the theoretical models; its application to a determined number of subjects; the application of other psychological tools for the study of convergent validity and for the verification of theoretical hypothesis; a factor analysis for item construction in the factors which will determine the final instruments and, finally, the study of the time stability for the test application and re-testing after a determined time lapse. The final results allow us to verify that it is possible to measure motivation for learning. We consider it is relevant to continue this research so that we may understand the students' real motivations. This analysis will be essential for the setting up of a set of strategies to fight school failure.

KEYWORDS: : Evaluate, motivation, teaching, learning, assessment scale 


\section{INTRODUÇÃO}

Todos os que são professores sabem, por experiência própria, que os alunos, na sua generalidade, têm uma grande falta de motivação para aprender os conteúdos letivos. Haverá, pelo certo, muitas razões para que tal ocorra, porém, estamos certos, de que todas elas podem ser determinantes no futuro dos estudantes. Qual é que será a fonte da desmotivação dos estudantes? O que os levará a trabalhar mais ou menos ou a preferir mais uma disciplina em detrimento de outra? Serão os conteúdos letivos em si, ou o processo metodológico a que o professor recorre o que mais determina a aprendizagem do aluno? Estas são algumas das questões que se procurará desenvolver ao longo deste trabalho.

De facto, se há uma desmotivação generalizada no processo de ensino/aprendizagem dos alunos, é compreensível que eles não tenham vontade de trabalhar os conteúdos que foram lecionados, de os estudar e, consequentemente, de os aprender.

As consequências desta desmotivação são óbvias e acabam por se manifestar aos mais diferentes níveis: falta de vontade para estudar, aborrecimento crónico, apatia escolar, ausência de expectativas de êxito, diminuição da própria autoestima, etc. Segundo Bzuneck (2001), os estudos realizados nos últimos anos confirmam que sem motivação não é possível a aprendizagem na escola.

Posto isto, no estudo que aqui se apresenta pretende-se construir e validar um instrumento para avaliar a motivação para a aprendizagem escolar.

\section{MOTIVAÇÃO PARA A APRENDIZAGEM}

A palavra motivação provém do latim movere, que significa "mover". A ideia de movimento é comum a muitas definições e relaciona-se com aquilo que é suscetível de levar o indivíduo a agir para atingir algo ou completar tarefas, mantendo-o na ação (Pintrich e Schunk, 2002, as cited in Siqueira e Wechsler, 2006).

Para Neves (2010, p. 36), a motivação pode ser definida como "um conjunto de processos de ativação e persistência do comportamento. Ser motivado é estar inspirado para uma ação específica, é ter iniciativa. O contrário, aquele que não possui tais características, é considerado desmotivado. No contexto ensino-aprendizagem, a motivação é o fator interno que impulsiona o aluno para estudar, iniciar os trabalhos e perseverar neles até ao fim".

Nos últimos anos, os estudos sobre a motivação para a aprendizagem e os agentes inerentes ao desempenho escolar têm sido objeto de interesse por muitos autores (Bzuneck, 2004, as cited in Boruchovitch e Neves, 2006). Com base na revisão da literatura especializada, pode-se constatar que a motivação do aluno é, a par de fatores como a inteligência, o contexto familiar e a condição socioeconómica, uma condicionante considerada relevante no processo ensinoaprendizagem, uma vez que influencia as aprendizagens e o desenvolvimento do aluno afetando o grau de investimento do mesmo nesse processo (Lemos, Soares, Almeida, 2000, p. 42). 0 aluno motivado procura novos conhecimentos e oportunidades, mostra-se entusiasmado e otimista na realização de tarefas, com disposição para novos desafios, envolvendo-se, assim, no processo de ensino-aprendizagem (Alcará e Guimarães, 2007). Segundo Stipek (2002, p.14). Pode dizer-se que 
um aluno está motivado quando se observam comportamentos que evidenciem vontade, gosto e empenho na resolução de uma atividade ou na aprendizagem de um item curricular.

Segundo as teorias sociocognitivas da motivação para a aprendizagem, existe o conceito de motivação intrínseca e extrínseca. Um aluno é intrinsecamente motivado quando se envolve e mantém na tarefa pela atividade em si, por ser interessante e geradora de satisfação. Os alunos executam as tarefas porque sentem prazer, simplesmente. Pelo contrário, quando um aluno realiza uma atividade ou tarefa para obter recompensas externas, materiais ou sociais, diz-se extrinsecamente motivado. Este está mais interessado na opinião de outros e desempenha as tarefas com o objetivo principal de agradar pais e/ou professores, receber elogios ou evitar castigos (Pfromm, 1987; Deci, Vallerand, Pelletier e Ryan, 1991; Lens, 1994; Pintrich e Schunk, 2002, as cited in Siqueira e Wechsler, 2006).

Estudos mais recentes vieram mostrar que a dicotomia entre motivação intrínseca e motivação extrínseca é evidente, mas limitada em representar todo o dinamismo próprio dos processos motivacionais (Simões e Alarcão, 2011). Diversos aspetos podem influenciar a motivação do aluno: "as expectativas e estilos dos professores, os desejos e aspirações dos pais e familiares, os colegas de sala, a estruturação das aulas, o espaço físico da sala de aula, o currículo escolar, a organização do sistema educacional, as políticas educacionais, e principalmente as próprias características individuais dos alunos" (Siqueira e Wechsler, 2006).

\subsection{AVALIAÇÃO DA MOTIVAÇÃO}

Estudar a motivação para a aprendizagem envolve a compreensão de um complexo sistema de fatores que se interrelacionam, operando em conjunto na motivação do aluno. Segundo Pintrich e Schunk (as cited in Siqueira e Wechsler, 2006) existem três métodos gerais para se avaliar a motivação para a aprendizagem: por meio de observações diretas, através do julgamento de outros e por questionários/escalas que seriam respondidos pelo próprio indivíduo a ser avaliado. Relativamente ao formato, o questionário é constituído por itens ou questões que procuram inquirir os atos e conviç̧ões do sujeito. Este atribui valores em escalas numéricas correspondendo às suas ações e crenças ao que está disposto na questão ou item.

Vários instrumentos foram elaborados conforme este padrão. Entre eles, encontra-se o trabalho de Boruchovitch e Neves (2006), que descreve os passos relativos à construção de uma escala para avaliar a motivação para aprender, a partir de alunos brasileiros, no ensino fundamental, e apresenta a análise preliminar de suas propriedades psicométricas. Siqueira e Wechsler (2006) constroem e validam um instrumento psicológico para avaliar a motivação para a aprendizagem escolar. Simões e Alarcão (2011), neste mesmo contexto, procedem à adaptação e validação de duas escalas breves de avaliação da motivação na aprendizagem: a Escala de Escolha Percebida na Aprendizagem e a Escala de Competência Percebida na Aprendizagem.

Os estudos citados anteriormente tinham como objetivo principal a elaboração (Boruchovitch e Neves, 2006; Siqueira e Wechsler, 2006) ou adaptação (Simões e Alarcão, 2011) e validação de uma escala ou questionário para avaliar a motivação. Em linhas gerais, o procedimento para a consecução deste objetivo compreende: a construção do instrumento, de acordo com pressupostos teóricos; a aplicação num número adequado de sujeitos; a aplicação de outros instrumentos psicológicos validados para o estudo da validade convergente e para verificação de hipóteses teóricas; a realização de uma Análise Fatorial para a composição dos itens 
nos fatores que determinaram o formato final do instrumento e, por fim, o estudo da estabilidade temporal por meio da aplicação do teste e do re-teste após um período de tempo.

De acordo com os resultados destes estudos pode-se inferir que é possível avaliar a motivação de forma válida, precisa e confiável.

\section{METODOLOGIA}

A metodologia pode ser vista como uma disciplina instrumental que tem como objetivo servir a pesquisa. Envolve todo o tipo de ciência e adota um conjunto vasto de métodos que tem como objetivo encontrar o sentido de um fenómeno observado (Chizzotti, 2003).

A metodologia pode derivar em processos qualitativos ou quantitativos. A diferença entre ambos foi motivo de grandes debates, especialmente quando se tratou de perceber da cientificidade de cada um deles. Após muitas contendas, ficou clara a necessidade da existência de ambos (Bogdan e Biklen, 1994).

Enquanto que os métodos qualitativos dão origem a dados descritivos que possibilita observar o modo de pensar dos participantes em determinada investigação, os métodos quantitativos permitem provar as relações entre as variáveis, possibilitando a medição da confiabilidade das medidas (Merriam, 1988).

\subsection{CONSTITUIÇÃO DA POPULAÇÃO E DA AMOSTRA}

Segundo Fortin $(1996,25)$ uma população é "uma coleção de elementos ou sujeitos que partilham características em comum, definidas por um conjunto de critérios". Por outro lado, a amostra refere-se ao grupo ou subconjunto de uma população, escolhida de forma a obter informações relacionadas com o fenómeno em estudo.

Neste sentido, a população deste estudo é constituída por estudantes do Colégio de São José, do concelho de Coimbra e ainda por adultos do sistema de Reconhecimento, Validação e Certificação de Competências (RVCC) do Centro de Novas Oportunidades (CNO) da Escola Básica de 2 e e 3 o ciclo de São Bernardo, do concelho de Aveiro.

Sendo este um universo constituído por um número elevado de elementos, selecionamos uma amostra, que consiste numa pequena parte da população em estudo.

Assim, recorrendo a uma amostra aleatória estratificada, com um nível de confiança de $90 \%$ e um erro amostral máximo de 5\%, inquirimos 181 estudantes, sendo 62 alunos do 3. e 4. anos do Ensino Básico, aos quais categorizamos como crianças; 79 alunos do 5.ํ, 6.ำ 7.ㅇ, 8.ㅇ e 9.o anos do Ensino Básico, aos quais classificamos como adolescentes e 41 alunos do Ensino Secundário inseridos no sistema de RVCC, que denominamos jovens/adultos.

Do total, 108 pertencem ao sexo feminino e 73 ao sexo masculino. A idade variou entre 8 e 60 anos, sendo a média de 18 anos. As escolas pertencem aos concelhos de Anadia, Aveiro e Coimbra. 


\subsection{INSTRUMENTO}

Para a recolha de dados foi utilizada uma escala criada para o estudo, a qual tinha como objetivo analisar a motivação para o estudo dos estudantes nas diferentes faixas etárias.

Com este fim, foram selecionadas as principais pesquisas (Boruchovitch e Neves, 2006; Siqueira e Wechsler, 2006) que tinham um objetivo similar, a construção de um instrumento de avaliação da motivação para a aprendizagem a nível escolar. Procedemos ao levantamento das características comuns na bibliografia específica já referenciada e, após um estudo detalhado, foram selecionadas as distintivas que melhor representavam a motivação para a aprendizagem escolar. Neste sentido, escolheram-se duas áreas de motivação:

a) Motivação extrínseca, que está relacionada com fatores externos ao aluno.

b) Motivação intrínseca, que está relacionada com fatores internos do aluno.

A primeira área é composta por 17 itens (tabela 1) e a segunda por 25 (tabela 2), perfazendo um total de 42 itens.

\section{Tabela 1: Itens associados à Motivação extrínseca}

1. Só faço tarefas escolares quando é pedido pelo professor

2. Sinto que é importante a opinião que os professores e colegas têm de mim

3. A opinião dos professores e colegas é muito importante para mim

4. Só estudo quando sei que vai haver teste

5. Gosto de ser elogiado por professores

6. Gosto de ser elogiado por colegas

7. Não me preocupo em estudar para ter uma boa profissão no futuro

8. Tenho a preocupação em ser visto pelos meus colegas como um bom aluno

9. Quero ser o melhor aluno da sala

10. Não me preocupo em ser considerado um bom aluno

11. Eu estudo com medo que os meus pais se chateiem comigo

12. Eu faço os trabalhos de casa por obrigação

13. Eu estudo porque os meus pais prometem compensar-me pelas minhas boas notas

14. Eu só estudo para não obter maus resultados

15. Eu só faço os trabalhos de casa porque os meus pais me obrigam

16. Eu só estudo porque quero tirar boas notas

17. Eu estudo por obrigação

Tabela 2: Itens associados à Motivação intrínseca
1. Estou mais preocupado em aprender do que tirar notas altas
2. Tenho boas notas porque me esforço para estudar
3. Em sala de aula gosto de realizar as tarefas propostas
4. Faço os exercícios mesmo quando o professor não vai dar nota
5. Detesto atividades para as quais tenho que pensar muito
6. Desisto rapidamente das minhas ideias quando encontro dificuldade
7. Não encontro motivação para estudar
8. Não gosto de nenhuma atividade escolar 
9. Gosto de fazer perguntas em sala de aula

10. Gosto de tarefas difíceis

11. Gosto de pesquisar para realizar uma atividade

12. Não consigo realizar as atividades escolares

13. Quando acredito numa ideia vou até ao fim

14. Adoro pesquisar sobre assuntos que estou a estudar na sala de aula, mesmo sem o professor pedir

15. Sinto-me incapaz de realizar a maioria das tarefas da escola

16. Tenho de me esforçar muito para ter um bom desempenho

17. Quando gosto de uma atividade em sala de aula não sinto o tempo a passar

18. Gosto de estudar

19. Eu estudo porque é importante para mim

20. Eu gosto de estudar assuntos difíceis

21. Eu estudo mesmo sem os meus pais me pedirem

22. Eu estudo mesmo sem os meus professores me pedirem

23. Eu estudo porque me dá prazer e alegria

24. Eu estudo porque quero aprender cada vez mais

25. Eu fico interessado quando o professor introduz novas matérias

A escala de motivação está organizada como uma escala de likert de 3 pontos, onde o aluno tinha de escolher uma de três respostas (concordo, não concordo nem discordo e não concordo).

Foi construído um instrumento de trabalho que foi aplicado a crianças, adolescentes e jovens/adultos.

\subsection{PROCEDIMENTO}

Numa primeira fase, foi aplicada uma pré-prova a 3 crianças, 3 adolescentes e 2 adultos com o objetivo de verificar a adequação da linguagem às diferentes faixas etárias. No inquérito aplicado a crianças e adolescentes teve de se proceder a uma adequação da linguagem e simbologia de forma a facilitar a interpretação do instrumento. No inquérito aplicado aos jovens/adultos, no qual foram ignoradas as questões relativas aos pais por não se adequar, não foi observada qualquer dúvida e dessa forma não de procedeu a qualquer alteração.

Os inquéritos foram aplicados, em horário letivo, no decurso das aulas dos investigadores, juntos dos seus estudantes, e teve uma duração média de 25 minutos.

Não se verificaram erros de preenchimento, pelo que todos os inquéritos aplicados foram considerados válidos.

Os dados foram analisados com recurso ao software estatístico SPSS versão 20.

Recorreu-se à Análise Fatorial de Componentes Principais para validar o construto e compor os fatores da escala de motivação. De forma a verificar a consistência interna dos fatores recorreu-se ao alfa de Cronbach.

De forma a testar a adequação das variáveis que entraram no modelo, verificou-se o valor do $\mathrm{KMO}$, que apresentou um valor considerado razoável de $0,65, \mathrm{p}<0,001$, sendo que a rotação convergiu em 20 iterações. 


\section{RESULTADOS}

Segundo Fortin (1996), a análise de dados "permite produzir resultados que podem ser interpretados pelo investigador". Com o objetivo de estudar a validade do construto da Escala de Aprendizagem recorreu-se, como já foi dito anteriormente, à Análise Fatorial de Componentes Principais, utilizando a rotação Varimax, a qual minimiza o número de variáveis que têm saturações altas em cada fator, reforçando a tendência para que se formem componentes não correlacionados. Deste modo, identificaram-se 14 fatores que explicam 66,3\% da variância abrangida nos dados originais da amostra.

Para a análise individual dos fatores, definiu-se que um item teria influência num fator se o seu valor absoluto fosse igual ou superior a 0,30. Para Kline (1994), este valor explica, pelo menos, $9 \%$ da variância total.

Para a composição dos itens, estipulou-se a existência de um mínimo de quatro por fator à semelhança de Siqueira e Wechsler (2006). Desta forma treze fatores foram eliminados, ficando apenas três. Contudo, ao analisar os fatores eliminados verificou-se a existência de um fator com apenas dois itens, mas com valores absolutos na ordem dos 0,7 , sendo por isso considerado um fator a não excluir.

Assim, após este processo analítico, a Escala de Motivação para a Aprendizagem ficou composta por quatro fatores que explicam $33,2 \%$ da variância total.

O fator 1 reuniu 19 itens, permitindo explicar 15,82\% da variância contida nos dados, é o fator claramente mais forte obtido nesta escala. Foi nomeado como Envolvimento/Persistência (tabela 3). Os itens deste fator prendem-se com o gosto pelas tarefas escolares, força de vontade para estudar, gosto por participar nas tarefas escolares, preferência por trabalhos novos e desafiantes.

Tabela 3: Composição do fator 1 da Escala de Motivação para a Aprendizagem

\begin{tabular}{lc}
\hline Descrição - Envolvimento/Persistência & Carga fatorial \\
\hline 4 - Só estudo quando sei que vai haver teste & $-0,45$ \\
8 - Tenho a preocupação em ser visto pelos meus colegas como um bom aluno & 0,54 \\
9 - Quero ser o melhor aluno da sala & 0,50 \\
19 - Tenho boas notas porque me esforço para estudar & 0,56 \\
20 - Em sala de aula gosto de realizar as tarefas propostas & 0,54 \\
21 - Faço os exercícios mesmo quando o professor não vai dar nota & 0,60 \\
22 - Detesto atividades para as quais tenho que pensar muito & $-0,60$ \\
23 - Desisto rapidamente das minhas ideias quando encontro dificuldade & $-0,39$ \\
24 - Não encontro motivação para estudar & $-0,42$ \\
26 - Gosto de fazer perguntas em sala de aula & 0,49 \\
27 - Gosto de tarefas difíceis & 0,46 \\
31 - Adoro pesquisar sobre assuntos que estou a estudar na sala de aula, mesmo sem o & 0,40 \\
professor pedir & 0,61 \\
35 - Gosto de estudar & 0,53 \\
37 - Eu gosto de estudar assuntos difíceis & 0,51 \\
38 - Eu estudo mesmo sem os meus pais me pedirem & 0,45 \\
39 - Eu estudo mesmo sem os meus professores me pedirem &
\end{tabular}



40 - Eu estudo porque me dá prazer e alegria
0,48
41 - Eu estudo porque quero aprender cada vez mais
0,55
42 - Eu fico interessado quando o professor introduz novas matérias
0,55

O fator 2 reuniu 5 itens e permite explicar 6,22\% da variância. Foi nomeado Obrigação/castigo/compensação (tabela 4). Os itens que compõem este fator prendem-se com o estudo por receio do castigo, pela necessidade de cumprir as regras impostas, pela promessa de compensação e pela necessidade de desenvolver esforço para atingir um bom desempenho.

Tabela 4: Composição do fator 2 da Escala de Motivação para a Aprendizagem

\begin{tabular}{lc}
\hline Descrição - Obrigação/castigo/compensação & Carga fatorial \\
\hline 11 - Eu estudo com medo que os meus pais se chateiem comigo & 0,47 \\
13 - Eu estudo porque os meus pais prometem compensar-me pelas minhas boas notas & 0,48 \\
15 - Eu só faço os trabalhos de casa porque os meus pais me obrigam & 0,54 \\
17 - Eu estudo por obrigação & 0,49 \\
33 - Tenho de me esforçar muito para ter um bom desempenho & 0,41 \\
\hline
\end{tabular}

O fator 3 reuniu 4 itens e permite explicar 5,81\% da variância. Foi nomeado Valorização pessoal (tabela 5). A composição deste fator agrega a necessidade de valorização por parte dos professores e colegas e ainda a preocupação de aumentar a sua valorização pessoal.

Tabela 5: Composição do fator 3 da Escala de Motivação para a Aprendizagem

\begin{tabular}{lc}
\hline Descrição - Valorização pessoal & Carga fatorial \\
\hline 2 - Sinto que é importante a opinião que os professores e colegas têm de mim & 0,43 \\
3 - A opinião dos professores e colegas é muito importante para mim & 0,44 \\
18 - Estou mais preocupado em aprender do que tirar notas altas & $-0,43$ \\
30 - Quando acredito numa ideia vou até ao fim & $-0,51$ \\
\hline
\end{tabular}

O fator 4 reuniu 2 itens e permite explicar $4,72 \%$ da variância. Foi nomeado Reconhecimento (tabela 6). Os itens que dão origem a este fator prendem-se com o aluno sentir necessidade do reconhecimento por parte dos outros.

Tabela 6: Composição do fator 4 da Escala de Motivação para a Aprendizagem

\begin{tabular}{lc}
\hline Descrição - Reconhecimento & Carga fatorial \\
\hline 5 - Gosto de ser elogiado por professores & 0,69 \\
6 - Gosto de ser elogiado por colegas & 0,75 \\
\hline
\end{tabular}

Os quatro fatores da escala foram posteriormente submetidos a uma análise de consistência interna dos seus itens. Para o efeito, recorreu-se ao alfa de Cronbach. Podemos ver, pela Tabela 7, que os fatores 1 e 4 da escala obtiveram os índices mais elevados, ambos acima dos 0,6 .

Tabela 7: Análise da consistência interna dos fatores da Escala de Motivação para a Aprendizagem

\begin{tabular}{cc}
\hline Fatores & Coeficiente Alfa \\
\hline F1 & 0,638 \\
F2 & 0,513 \\
F3 & 0,298 \\
F4 & 0,637 \\
\hline
\end{tabular}


Como nos é dado observar, a consistência interna dos fatores não é propriamente alta. Todavia, ainda assim, regista-se uma diferença explícita entre eles, já que os fatores 1 e 4 apresentam, segundo as medidas de Guay Boggiano e Vallerand (2001), valores muito próximos de uma razoável aceitabilidade, sendo que o fator 3 fica muito aquém de uma consistência desejável.

\section{REFERÊNCIAS BIBLIOGRÁFICAS}

1. ALCARÁ, A., GUIMARÃES, S. A instrumentalidade como uma estratégia motivacional. Psicologia Escolar e Educacional, II (1), 2007, 177-178.

2. BOGDAN, R., BIKLEN, S. Investigação Qualitativa em Educação- uma introdução à teoria e aos métodos. Porto: Porto Editora, 1994.

3. COUTINHO, C. P. Metodologia de Investigação em Ciências Sociais e Humanas: teoria e prática. Coimbra: Edições Almedina, 2011.

4. CHIZZOTTI, A. A pesquisa qualitativa em Ciências Humanas e Sociais: Evolução e desafios. Universidade do Minho: Revista Portuguesa de Educação, 16 (2), 2003, 221-236.

5. BORUCHOVITCH, E., Neves, E. Escala de avaliação da motivação para aprender de alunos do Ensino Fundamental. Psicologia: Reflexão e Crítica, 20 (3), 2006, 406-413

6. BZUNECK, J. A motivação do aluno: aspetos introdutórios. In: Boruchovitch, E.; Bzuneck, J. (Org.). Motivação do aluno: contribuições da psicologia contemporânea. Petrópolis, RJ: Vozes, 2001, 9-36.

7. CANTORI, W., NEVES, E. Orientações motivacionais de alunos do curso superior: estudo exploratório com estudantes do curso de comunicação social. Revista Interdisciplinar do Centro Universitário Adventista de São Paulo, 18 (1), 2010, 35-46.

8. DUQUE, E. Representações e Expectativas dos Estudantes Universitários dos PALOP. 7o Congresso Português de Sociologia. Porto, 19-22 Junho, 2012.

9. FERREIRA, V. O inquérito por questionário na construção de dados sociológicos. In: Silva, A.; Pinto, J. (Org.). Metodologia das Ciências Sociais. 15.a edição. Porto: Afrontamento, 2009, 165196.

10. FORTIN, M. O Processo de Investigação: da concepção à realização. 1.a edição. Lisboa: Lusociência, 1996.

11. GUAY, F., BOGGIANO, A., VALLERAND, R. Autonomy support, intrinsic motivation and perceived competence: conceptual and empirical linkages. Personality and Social Psychology Bulletin, 27, 2001, 643-650.

12. GUIMARÃES, S., BZUNECK, J. Propriedades psicométricas de uma medida de avaliação da motivação intrínseca e extrínseca: um estudo exploratório. Psico-USF, 7, 2002, 1-8.

13. KLINE, P. An easy guide to factor analysis. New York: Routledge, 1994.

14. LEMOS, M., SOARES, I., ALMEIDA, C. Estratégias de motivação em adolescentes. Psicologia: Teoria, Investigação e Prática, 2000.

15. LOURENÇO, A., PAIVA, M. A motivação escolar e o processo de aprendizagem. Ciências \& Cognição, 15 (2), 2010, 132-141. 
16. MERRIAM, S. Case study research in education: A qualitative approach. San Francisco, CA: Jossey-Bass, 1988.

17. NUNNALLY, J. C. Psychometric Theory. McGraw Hill: New York, 1967.

18. PASQUALI, L. Psicometria - Teoria dos Testes na Psicologia e Educação. Petrópolis: Vozes, 2003.

19. PEREIRA, J. Análise de dados qualitativos: Estratégias metodológicas para as ciências da saúde, humanas e sociais. São Paulo: Edusp, 2001.

20. SIQUEIRA, L., WECHSLER, S. Motivação para a aprendizagem escolar: possibilidade de medida. Avaliação psicológica, 5 (1), 2006, 21-31.

21. SIMÕES, F., ALARCÃO, M. Avaliação da motivação intrínseca na aprendizagem: validação de duas escalas para crianças e adolescentes. Psico-USF, 16 (3), 2011, 265-273. 


\section{ANEXOS}

\section{INQUÉRITO}

O questionário é anónimo, as respostas confidenciais. Leia atentamente as instruções que lhe são dadas, certificando-se que compreendeu corretamente o modo como deverá responder. Não há respostas certas ou erradas, responda sempre de acordo com o que faz, sente ou pensa.

Agradecemos a sua colaboração.

\section{Informações:}

Idade:

Sexo: $F(\ldots) M(\ldots)$

Escola:

Ano:

Localidade:

Para cada umas das afirmações propostas, marque com uma cruz a casa correspondente à sua opinião. Marque (x) 1 se concorda com a afirmação, (x) 2 se não concorda, nem discorda e (x) 3 se discorda da afirmação.

\begin{tabular}{|c|c|c|c|c|}
\hline $1=\operatorname{Sim}$ & $2=$ Nem Sempre & $\stackrel{1}{(0)}$ & $\stackrel{2}{(-)}$ & $\stackrel{3}{\%}$ \\
\hline 1 & Só faço tarefas escolares quando é pedido pelo professor & & & \\
\hline 2 & Sinto que é importante a opinião que os professores e colegas têm de mim & & & \\
\hline 3 & A opinião dos professores e colegasé muito importante para mim & & & \\
\hline 4 & Só estudo quando sei que vai haver teste & & & \\
\hline 5 & Gosto de ser elogiado por professores & & & \\
\hline 6 & Gosto de ser elogiado por colegas & & & \\
\hline 7 & Não me preocupo em estudar para ter uma boa profissão no futuro & & & \\
\hline 8 & Tenho a preocupação em ser visto pelos meus colegas como um bom aluno & & & \\
\hline 9 & Quero ser o melhor aluno da sala & & & \\
\hline 10 & Não me preocupo em ser considerado um bom aluno & & & \\
\hline 11 & Eu estudo com medo que os meus pais se chateiem comigo & & & \\
\hline 12 & Eu faço os trabalhos de casa por obrigação & & & \\
\hline 13 & $\begin{array}{l}\text { Eu estudo porque os meus pais prometem compensar-me pelas minhas boas } \\
\text { notas }\end{array}$ & & & \\
\hline 14 & Eu só estudo para não obter maus resultados & & & \\
\hline 15 & Eu só faço os trabalhos de casa porque os meus pais me obrigam & & & \\
\hline 16 & Eu só estudo porque quero tirar boas notas & & & \\
\hline 17 & Eu estudo por obrigação & & & \\
\hline 18 & Estou mais preocupado em aprender do que tirar notas altas & & & \\
\hline 19 & Tenho boas notas porque me esforço para estudar & & & \\
\hline
\end{tabular}




\begin{tabular}{|c|c|c|c|c|}
\hline $1=\operatorname{Sim}$ & $2=$ Nem Sempre & $\left(\begin{array}{c}1 \\
(\end{array}\right.$ & $\stackrel{2}{\ominus}$ & $\stackrel{3}{6}$ \\
\hline 20 & Em sala de aula gosto de realizar as tarefas propostas & & & \\
\hline 21 & Faço os exercícios mesmo quando o professor não vai dar nota & & & \\
\hline 22 & Detesto atividades para as quais tenho que pensar muito & & & \\
\hline 23 & Desisto rapidamente das minhas ideias quando encontro dificuldade & & & \\
\hline 24 & Não encontro motivação para estudar & & & \\
\hline 25 & Não gosto de nenhuma atividade escolar & & & \\
\hline 26 & Gosto de fazer perguntas em sala de aula & & & \\
\hline 27 & Gosto de tarefas dificeis & & & \\
\hline 28 & Gosto de pesquisar para realizar uma atividade & & & \\
\hline 29 & Não consigo realizar as atividades escolares & & & \\
\hline 30 & Quando acredito numa ideia vou até ao fim & & & \\
\hline 31 & $\begin{array}{l}\text { Adoro pesquisar sobre assuntos que estou a estudar na sala de aula, mesmo sem } \\
\text { o professor pedir }\end{array}$ & & & \\
\hline 32 & Sinto-me incapaz de realizar a maioria das tarefas da escola & & & \\
\hline 33 & Tenho de me esforçar muito para ter um bom desempenho & & & \\
\hline 34 & Quando gosto de uma atividade em sala de aula não sinto o tempo a passar & & & \\
\hline 35 & Gosto de estudar & & & \\
\hline 36 & Eu estudo porque é importante para mim & & & \\
\hline 37 & Eu gosto de estudar assuntos dificeis & & & \\
\hline 38 & Eu estudo mesmo sem os meus pais me pedirem & & & \\
\hline 39 & Eu estudo mesmo sem os meus professores me pedirem & & & \\
\hline 40 & Eu estudo porque me dá prazer e alegria & & & \\
\hline 41 & Eu estudo porque quero aprender cada vez mais & & & \\
\hline 42 & Eu fico interessado quando o professor introduz novas matérias & & & \\
\hline
\end{tabular}

Ilustração 1 - Inquérito aplicado a crianças 


\section{INQUÉRITO}

O questionário é anónimo, as respostas confidenciais. Leia atentamente as instruções que lhe são dadas, certificando-se que compreendeu corretamente o modo como deverá responder. Não há respostas certas ou erradas, responda sempre de acordo com o que faz, sente ou pensa.

Agradecemos a sua colaboração.

\section{Informações:}

Idade:

Sexo: $F(\ldots .) M.(\ldots$.

Escola:

Ano:

Localidade:

Para cada umas das afirmações propostas, marque com uma cruz a casa correspondente à sua opinião. Marque (x) 1 se concorda com a afirmação, (x) 2 se não concorda, nem discorda e (x) 3 se discorda da afirmação.

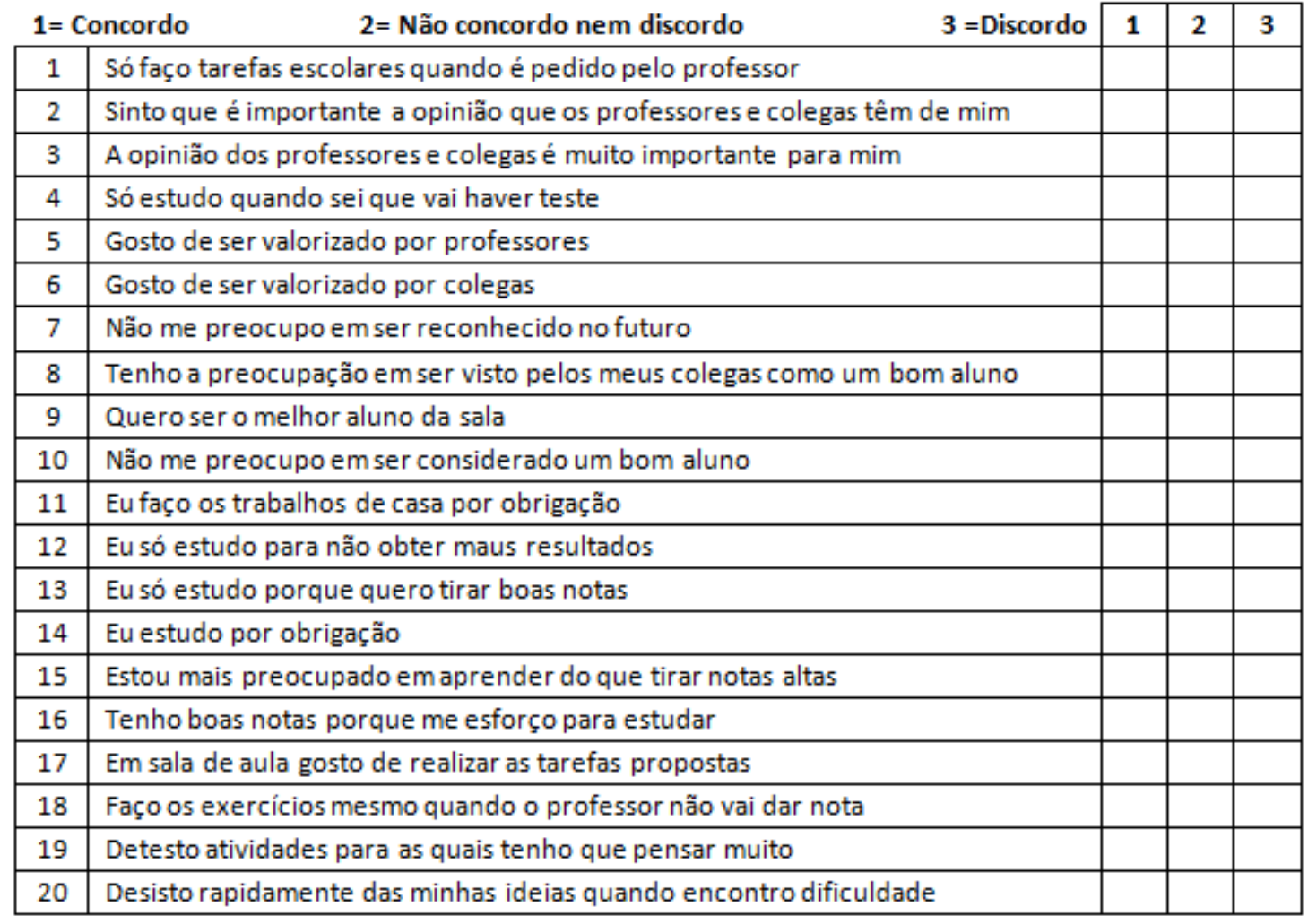

v.s.f.f. 


\begin{tabular}{|c|c|c|c|c|}
\hline \multicolumn{2}{|c|}{$1=$ Concordo } & \multirow[t]{2}{*}{1} & \multirow[t]{2}{*}{2} & \multirow[t]{2}{*}{3} \\
\hline 21 & Não encontro motivação para estudar & & & \\
\hline 22 & Não gosto de nenhuma atividade escolar & & & \\
\hline 23 & Gosto de fazer perguntas em sala de aula & & & \\
\hline 24 & Gosto de tarefas dificeis & & & \\
\hline 25 & Gosto de pesquisar para realizar uma atividade & & & \\
\hline 26 & Não consigo realizar as atividades escolares & & & \\
\hline 27 & Quando acredito numa ideiavou até ao fim & & & \\
\hline 28 & $\begin{array}{l}\text { Adoro pesquisar sobre assuntos que estou a estudar na sala de aula, mesmo sem } \\
\text { o professor pedir }\end{array}$ & & & \\
\hline 29 & Sinto-me incapaz de realizar a maioria das tarefas da escola & & & \\
\hline 30 & Tenho de me esforçar muito para ter um bom desempenho & & & \\
\hline 31 & Quando gosto de uma atividade em sala de aula não sinto o tempo a passar & & & \\
\hline 32 & Gosto de estudar & & & \\
\hline 33 & Eu estudo porque é importante para mim & & & \\
\hline 34 & Eu gosto de estudar assuntos desafiantes & & & \\
\hline 35 & Eu gosto de estudar assuntos dificeis & & & \\
\hline 36 & Eu estudo mesmo sem me pedirem & & & \\
\hline 37 & Eu estudo porque me dá prazer e alegria & & & \\
\hline 38 & Eu estudo porque quero aprender cada vez mais & & & \\
\hline 39 & Eu fico interessado quando o professor introduz novos conteúdos & & & \\
\hline
\end{tabular}

Ilustração 2 - Inquérito aplicado a adultos 